\title{
Organisation of inner cellular components as reported by a viscosity-sensitive fluorescent Bodipy probe suitable for phasor approach to FLIM
}

Gianmarco Ferri, ${ }^{a}$ Luca Nucara,${ }^{b}$ Tarita Biver, ${ }^{c}$ Antonella Battisti, ${ }^{a, d}$ Giovanni Signore $, *, b$ Ranieri

Bizzarri $*, a, c$

aNEST, Scuola Normale Superiore and NANO-CNR, Pisa, Italy.

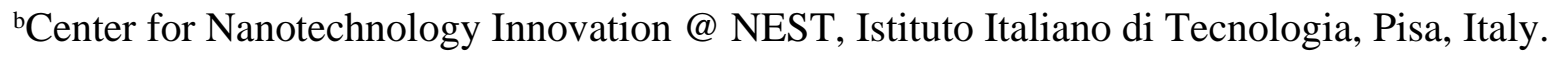

`Dipartimento di Chimica e Chimica Industriale, Università di Pisa, 56126 Pisa, Italy

distituto di Biofisica -CNR, via Moruzzi 1, 56124, Pisa, Italy.

KEYWORDS: molecular rotor, intracellular viscosity, FLIM, phasor approach, Hutchinson-

Guilford progeria syndrome, chromatin compaction 


\section{ABSTRACT}

According to the recent developments in imaging strategies and in tailoring fluorescent molecule as probe for monitoring biological system, we coupled a Bodipy-based molecular rotor (BoMe) with FLIM phasor approach to evaluate the viscosity in different intracellular domains. BoMe rapidly permeates cells, stains cytoplasmic as well as nuclear domains, and its optical properties make it perfectly suited for widely diffused confocal microscopy imaging setups. The capability of BoMe to report on intracellular viscosity was put to the test by using a cellular model of a morbid genetic pathology (Hutchinson-Gilford progeria syndrome, HGPS). Our results show that the nucleoplasm of HGPS cells display reduced viscosity as compared to normal cells. Since BoMe displays significant affinity towards DNA $\left(\mathrm{K}=8500 \mathrm{M}^{-1}\right)$, as demonstrated by an in vitro essay, we hypothesize that genetic features of HGPS, namely the misassembly of lamin A protein within the nuclear lamina, modulates chromatin compaction. This hypothesis nicely agrees with literature data. 


\section{INTRODUCTION}

In the last two decades, fluorescent molecules drastically increased our capacity to monitor biological systems at the cellular and subcellular level by fluorescence microscopy [1-3]. This prompted a strong effort towards the synthesis of new and ever more effective fluorescent probes tailored to a broad range of applications, including the characterization at nanoscale of the cellular environments where relevant biological processes take place [4-7]. In this context, ideal probes should combine good emission properties in the visible, high sensitivity towards specific molecular or physicochemical determinants, and low photo-toxicity. Another required feature is the capability to provide a quantitative fluorescence signal irrespective of excitation-light intensity or probe concentration [8]. Indeed, the control of probe concentration is very difficult to achieve in experiments targeting intracellular environments. This requirement is satisfied by $\lambda$-ratiometry, an imaging method based on the steady-state intensity ratio computed at two or more wavelengths [9]. Yet, $\lambda$-ratiometry requires fluorescent probes whose excitation and/or emission spectra are displaced by intermolecular interactions. Typically this is achieved by fusing together two emitting units with opposite optical behavior with respect to the parameter to be monitored [9]. As a consequence, the design and synthesis of such probes may be complex. Fluorescence lifetime imaging (FLIM) constitutes an excellent alternative to $\lambda$-ratiometry, given the strong sensitivity of fluorescence lifetime to biomolecular interactions conjugated with its independence from the probe concentration [10, 11]. In most cases FLIM is carried out by recording the time decay of fluorescence in each image pixel by accumulating the stochastic time arrivals of single photons [12]. The main drawback of conventional FLIM is, however, the low number of photons per pixel ( 500-1000) that can be collected in a typical measurement. This signal is barely enough to distinguish a single from a double exponential decay, which represents the minimum requirement to decide if at least two emitting species/states are concomitantly present in the same pixel. To address 
this issue, Gratton et al. developed the phasor approach to FLIM [13], a graphic method that adopts the perspective of frequency domain lifetime measurement [14]. In the phasor approach to FLIM, the emission decay in each pixel maps into a vector lying in a polar 2D plot (phasor plot), and sample regions associated with different lifetimes are immediately identifiable [15]. Additionally, combinations of different lifetimes follow simple vectorial addition rules, allowing for the calculation of the intensity fraction due to each component. Several groups, including us, applied successfully the phasor approach to FLIM to follow a broad range of intracellular processes including biomolecular interactions [16] and ion homeostasis [17].

Recently, we reported on the use of phasor approach to FLIM for monitoring local viscosity at intracellular level [18]. The reliable determination of micro/nanoviscosity in cell domains is particularly relevant from a biophysical perspective, since diffusion-controlled reactions and events are fundamental to many biological processes [19]. Fluorescent probes sensitive to local viscosity are referred to as molecular rotors [19]. Molecular rotors perceive local viscosity through intramolecular twisting motion(s) that occur at excited state [20]. Slowing of the twisting motions as viscosity increases leads to stronger emission and longer lifetime decay [21]. Most often a log$\log$ relationship between viscosity and quantum yield or lifetime holds, as predicted by Forster and Hoffmann [22]. In our previous study [18], we demonstrated that the phasor plot is perfectly suited to determine local viscosity in cell domains after a reliable in vitro calibration, although our probe was characterized by a molecular structure that targeted it prevalently in mitochondria. In view of expanding our strategy to monitor intracellular lifetime, we here report on a different molecular rotor (BoMe) suitable for the phasor approach to FLIM. This rotor belong to the 4,4'-difluoro-4bora-3a,4a-diaza-s-indacene (Bodipy) family, has no net charge, and it carries a phenyl substituent in meso position (Scheme 1). As described for similar structures [7], the viscosity dependence of fluorescence emission and lifetime is attributable to the kinetically-restricted rotation of the phenyl group with respect to the dipyrrin core, which hampers non-radiative decay channels [23, 24]. 
Notably, the present study demonstrates that BoMe is able to permeate living cells and stain most cell domains including the nucleoplasm, presumably at DNA level. On account of our long-standing interest in biological process occurring at the border and inside the cell nucleus [25-27], we here apply BoMe to monitor intranuclear viscosity in cells characterized by defective nuclear lamina (NL) assembly. NL is a fibrillar network located between the inner nuclear membrane of eukaryotic cells and chromatin-containing nucleoplasm [28]. For years, NL was thought to be essential solely to the nucleus integrity. Recent data, instead, indicate that NL plays a relevant role in many fundamental cellular functions [29]. The peculiar role of NL in cell and the quest for increasing knowledge about this structure is dramatically demonstrated by a wide range of inherited lifethreatening diseases (laminopathies) that stem from sequence mutation in the proteins constituting NL, B-type lamins (LaB) and A-type lamins (LaA) [30]. One specific mutation in Lamin-A gene (LMNA) leads to nuclear architectural defects and is at basis of Hutchinson-Gilford progeria syndrome (HGPS), an extremely rare genetic disorder that causes premature, rapid aging shortly after birth [30, 31]. Yet, while the genetic and protein processing defects in HGPS are clearly defined, the mechanism by which progerin mediates defects at cellular level are largely unknown. We shall show here that BoMe measures different viscosity values in the nucleoplasm of HGPS cells as compared to normal cells, thus suggesting modification in chromatin compaction as result of mutated LaA assembly. These results clearly highlight BoMe as a promising tool for biological studies addressing different cell compartments, particularly the nucleus. 


\section{MATERIALS AND METHODS}

\section{Synthesis of BoMe}

Nomenclature of the synthetic intermediates refers to Scheme 1.

\section{Methyl (4-formylphenoxy)acetate (1)}

4-hydroxybenzaldehyde (2.00 g, $16.4 \mathrm{mmol})$ was dissolved in acetone (45 ml). $2.78 \mathrm{~g} \mathrm{(20} \mathrm{mmol)} \mathrm{of}$ potassium carbonate and $2.1 \mathrm{ml}(20 \mathrm{mmol})$ of methyl bromoacetate were added, and the resulting mixture was refluxed for $3 \mathrm{~h}$. After, the reaction was cooled to room temperature, diluted with water and extracted with $\mathrm{Et}_{2} \mathrm{O}$. The organic phase was washed with water and brine, dried over $\mathrm{Na}_{2} \mathrm{SO}_{4}$ and concentrated under reduced pressure, obtaining a yellow oil that was treated with toluene and dried in vacuum. We obtained $2.85 \mathrm{~g}(14.7 \mathrm{mmol}, 89 \%$ yield $)$ of the desired product as a pale yellow solid.

${ }^{1} \mathrm{H}$ NMR (300 MHz, DMSO-d6) $\delta(\mathrm{ppm}): 9.87(\mathrm{~s}, 1 \mathrm{H}), 7.86(\mathrm{~d}, \mathrm{~J}=8.7 \mathrm{~Hz}, 2 \mathrm{H}), 7.12(\mathrm{~d}, \mathrm{~J}=8.7$ $\mathrm{Hz}, 2 \mathrm{H}), 4.95(\mathrm{~s}, 2 \mathrm{H}), 3.7(\mathrm{~s}, 3 \mathrm{H})$

${ }^{13} \mathrm{C}$ NMR (300 MHz, DMSO-d6) $\delta$ (ppm): 191.9, 169.2, 162.9, 132.2, 130.6, 115.5, 65.1, 52.4

\section{Methyl [4-(di-1H-pyrrol-2-ylmethyl)phenoxy]acetate (2)}

$476 \mathrm{mg}(2.5 \mathrm{mmol})$ and $91 \mathrm{mg}(0.3 \mathrm{mmol})$ of $\mathrm{InBr}_{3}$ were introduced under nitrogen in a $50 \mathrm{ml}$ threenecked round bottom flask containing $17 \mathrm{ml}(0.25 \mathrm{~mol})$ of freshly distilled pyrrole. The mixture was stirred at room temperature in dark. After 3 h, $280 \mathrm{mg}(6.9 \mathrm{mmol})$ of finely triturated solid $\mathrm{NaOH}$ were added to the solution. The reaction was stirred for further $45 \mathrm{~min}$ at the same temperature. The reaction mixture was filtered and the solution was evaporated under reduced pressure. The obtained residue was purified by flash chromatography on silica (eluent: cyclohexane/AcOEt), affording to $546 \mathrm{mg}$ (1.8 mmol, $70 \%$ yield) of compound 2 , as a yellow oil. The intermediate was used directly in the subsequent reaction 
Boron difluoro[methyl-[2-[4-(1H-pyrrol-2-yl-2H-pyrrol-2-ylidenemethyl)phenoxy]acetate]]

(BoMe)

$395 \mathrm{mg}(1.7 \mathrm{mmol})$ of DDQ were introduced in a $100 \mathrm{ml}$ three-necked round bottom flask, containing $540 \mathrm{mg}(1.7 \mathrm{mmol})$ of compoud 2 and $25 \mathrm{ml}$ of dry toluene, obtaining a black mixture that was stirred at room temperature. After $1 \mathrm{~h}, 3 \mathrm{ml}(1.7 \mathrm{mmol})$ of $N, N$-diisopropylethylamine were added, followed immediately by $2.5 \mathrm{ml}(20.4 \mathrm{mmol})$ of boron trifluoride etherate, resulting in a dark red mixture that was stirred at room temperature for one hour. The reaction was decanted from the dark green sludge which was thoroughly washed with toluene. The combined organic phases were washed with water, dried over $\mathrm{Na}_{2} \mathrm{SO}_{4}$ and the solvents were removed in vacuo. The crude product was purified by flash chromatography on silica (eluent: cyclohexane/AcOEt), obtaining $224 \mathrm{mg}(0.6$ mmol, $37 \%$ yield) of compound $\mathbf{3}$, as a red-orange solid.

${ }^{1} \mathrm{H}$ NMR (300 MHz, DMSO-d6) $\delta$ (ppm): 8.10 (bs, 2H), $7.66(\mathrm{~d}, \mathrm{~J}=8.8 \mathrm{~Hz}, 2 \mathrm{H}), 7.17$ (d, J = 8.8 Hz, 2H), 7.05 (d, J=4.2 Hz, 2H), 6.69 (dd, J1 = 4.2, J2 = 1.9 Hz, 2H), 4.95 (s, 2H), 3.74 (s, 3H)

${ }^{13} \mathrm{C}$ NMR (300 MHz, DMSO-d6) $\delta$ (ppm): 169.5, 160.7, 147.2, 144.6, 134.5, 133.1, 132.1, 126.6, $119.5,115.5,65.1,52.5$

Mass required for $\mathrm{C}_{18} \mathrm{H}_{15} \mathrm{BF}_{2} \mathrm{~N}_{2} \mathrm{O}_{3}$ : 356.1; found: $357.4(\mathrm{M}+\mathrm{H})^{+}$

\section{Chemical characterization methods}

LC-MS analyses were performed on a Dionex Ultimate 3000 HPLC, equipped with automated fraction collector, PDA detector, and interfaced with an ABSciex 3200 QTRAP mass spectrometer, using water and trifluoracetic acid (TFA) $0.01 \%$ (solvent A)/ACN and TFA $0.01 \%$ (solvent B) as mobile phase. LC-MS analyses were performed on a Phenomenex Luna C-18 column $(3 \times 150 \mathrm{~mm}$, particle size 5 um, 100 A). Preparative purifications were performed on an Isco Teledyne RF system, using the appropriate mobile phase. 
NMR analyses were performed on a Bruker Avance III $300 \mathrm{MHz}$ spectrometer at room temperature in DMSO- $\mathrm{d}^{6}$.

\section{Calibration mixtures for viscosity}

Calibrating solutions were prepared by mixing known weights of methanol and glycerol or isoamyl alcohol and Triton X-100, respectively. Viscosity was estimated from weight fractions as described in [32].

\section{BoMe samples for spectroscopy}

For steady-state measurements, solutions of BoMe in the selected solvents were placed in quartz cuvettes with $1 \mathrm{~cm}$ absorption/excitation optical path (Hellma, Milan, Italy); concentration of the fluorophore was adjusted to obtain $0.08-0.1$ optical density and provide linearity between fluorescence emission and absorbance.

\section{Steady-state optical measurements}

Absorption spectra were recorded at $25{ }^{\circ} \mathrm{C}$ by a JASCO V550 spectrophotometer (JASCO Europe, Italy) using $1 \mathrm{~nm}$ band-pass and $0.25 \mathrm{~s}$ integration time. Fluorescence intensity spectra were recorded at $25^{\circ} \mathrm{C}$ by either a Fluoromax-4 fluorometer (Jobin-Yvon, Milan, Italy) or a PerkinElmer LS55 fluorometer with 1-5 nm excitation/emission bandpass and 0.2-0.5 s integration time. The perkin-Elmer fluorometer was equipped with jacketed cell holders, providing temperature control to within $\pm 0.1^{\circ} \mathrm{C}$. Quantum yield and corrected fluorescence spectra were determined according to standard procedures [33].

\section{Plasmid vectors}

The DsRed-LaA and DsRed-HGPS plasmids were kindly provided us by Prof. Albert Busch from Wurzuburg University [34]. These plasmids were amplified in One Shot Top10 Chemically 
Competent E. coli (Invitrogen) by classical heat-shock transformation protocol $\left(42^{\circ} \mathrm{C} \times 45^{\prime}\right.$ ') in order to use for electroporation protocol.

\section{Cell cultures and electroporation}

U2OS cells were grown in Dulbecco's modified Eagle medium: F-12 nutrient mix (D-MEM/F12) purchased from Invitrogen (Carlsbad,CA) supplemented with $10 \%$ fetal bovine serum and 100 $\mathrm{U} / \mathrm{ml}$ penicillin, and $100 \mathrm{mg} / \mathrm{ml}$ streptomycin (Invitrogen). Cells were maintained at $37{ }^{\circ} \mathrm{C}$ in a humidified $5 \% \mathrm{CO}_{2}$ atmosphere. The electroporation of DsRed-LaA plasmid and DsRed-HGPS plasmid were carried out using Digital Bio Microporator according to manufacturer's instructions. For fluorescence lifetime imaging, 120000 cells were plated onto a 35-mm glass-bottom dish (WillCo-dish GWSt-3522), once electroporation is done.

\section{Fluorescence microscopy imaging of living cells}

Living U2OS, placed in glass bottom WillCo dishes, were treated for 15 min with $1 \mu \mathrm{M}$ of BoMe solution and mounted in a thermostated chamber at $37^{\circ} \mathrm{C}$ (Leica Microsystems) humidified with 5 $\% \mathrm{CO} 2$ atmosphere.

Fluorescence imaging was carried out by a confocal scanning laser microscope Leica TCS SP5 (Leica Microsystems, Mannheim, Germany) according to two operating modes: confocal imaging and confocal FLIM. For confocal imaging, cells were observed by exciting at $488 \mathrm{~nm}$ (cw Argon laser, $10-20 \mu \mathrm{W}$ at the sample) and collecting the emission in the 500-580 $\mathrm{nm}$ range. For confocal FLIM, cells were observed by exciting at $470 \mathrm{~nm}$ with a pulsed diode laser operating at $40 \mathrm{MHz}$ (average power: $10-20 \mu \mathrm{W}$ at the sample), and collecting the emission in the $500-580 \mathrm{~nm}$ range by a photomultiplier tube interfaced with a Time Correlated Single Photon Counting card and setup (PicoHarp 300, PicoQuant, Berlin); FLIM acquisitions lasted until 100-200 photons were collected 
on average in each pixel. For phasor analysis, confocal FLIM images were elaborated using SimFCS software (available at www.lfd.uci.edu).

In all imaging modes, cells were viewed with a 40x 1.25 NA or $100 \mathrm{x} 1.4$ NA oil immersion objectives (Leica Microsystems, Berlin, Germany). Line scanning speeds ranged from 200 to 1400 $\mathrm{Hz}$, depending on the sample fluorescence and optical zoom. The pinhole aperture was set to 1.0 Airy. Imaging data were analyzed by ImageJ software (National Institutes of Health, Bethesda, MD).

\section{Interaction of BoMe with DNA}

Calf thymus DNA (from now on DNA) was purchased from Sigma-Aldrich in the form of lyophilised sodium salt, dissolved into water and sonicated to reduce the polynucleotide length (to ca. 800 base pairs) following an already described procedure [35]. Stock solutions of DNA were standardised spectrophotometrically using $\varepsilon=13,200 \mathrm{M}^{-1} \mathrm{~cm}^{-1}$ at $260 \mathrm{~nm}, \mathrm{I}=0.1 \mathrm{M}(\mathrm{NaCl}), \mathrm{pH}=$ 7.0 [36]. The DNA concentrations are expressed in molarity of base-pairs and will be indicated as $\mathrm{C}_{\mathrm{P}}$, whereas in these studies the dye concentration is indicated as $\mathrm{C}_{\mathrm{D}}$. Sodium cacodylate $(2.5 \mathrm{mM})$ was employed to keep the $\mathrm{pH}$ of the solutions at the value of 7.0. Doubly distilled water was used throughout. DNA fluorescence titrations were carried out at $25.0 \pm 0.1^{\circ} \mathrm{C}$ by adding increasing amounts of the polynucleotide directly into the cell $(1 \mathrm{~cm}$ path length) that contained dye solution. The additions were made by a Hamilton microsyringe connected to a Mitutoyo micrometric screw; such system enables minimum additions as small as $0.166 \mu \mathrm{L}$. Fluorescence titrations were analysed at $\lambda_{\mathrm{ex}}=470 \mathrm{~nm}$ and $\lambda_{\mathrm{em}}=512 \mathrm{~nm}$. 


\section{RESULTS AND DISCUSSIONS}

\section{Synthesis of Boron difluoro[methyl-[2-[4-(1H-pyrrol-2-yl-2H-pyrrol-2-ylidenemethyl)-}

phenoxy]acetate]] (BoMe) - Synthesis of BoMe was carried out according the synthetic strategy depicted in Scheme 1 and based on condensation between pyrrole and aromatic aldehydes. This approach was proved to be very effective when non-substituted pyrroles are used as building blocks [37]. In more details, alkylation of commercially available $p$-hydroxybenzaldehyde with methyl bromoacetate afforded intermediate $\mathbf{1}$ in excellent yield (89\%) and without the need for chromatographic purification (Scheme 1). This compound was condensed in the presence of an excess of pyrrole using indium bromide as a catalyst, leading to $\mathbf{2}$ that was isolate in pure form after flash-chromatography (Scheme 1). Finally, oxidation of dipyrromethane to dipyrromethene was accomplished by oxidation with DDQ, according to a reported procedure for a structurally-related compound [7]. This intermediate was reacted one-pot with $\mathrm{BF}_{3} \mathrm{Et}_{2} \mathrm{O}$, leading to the target compound BoMe. The product was recovered in moderate (37\%) yield after column chromatography. The yield obtained in the last step is in keeping with what previously reported for analogous Bodipy derivatives, and it is likely due to the scarce chemical stability of intermediate dipyrromethanes and dipyrromethene derivatives prior to reaction with $\mathrm{BF}_{3} \cdot \mathrm{Et}_{2} \mathrm{O}$ [37]. Note that the ester functional group present on BoMe is exploitable for further chemical conjugation with target biomolecules upon hydrolysis under aqueous basic conditions. This topic will be discussed elsewhere. 


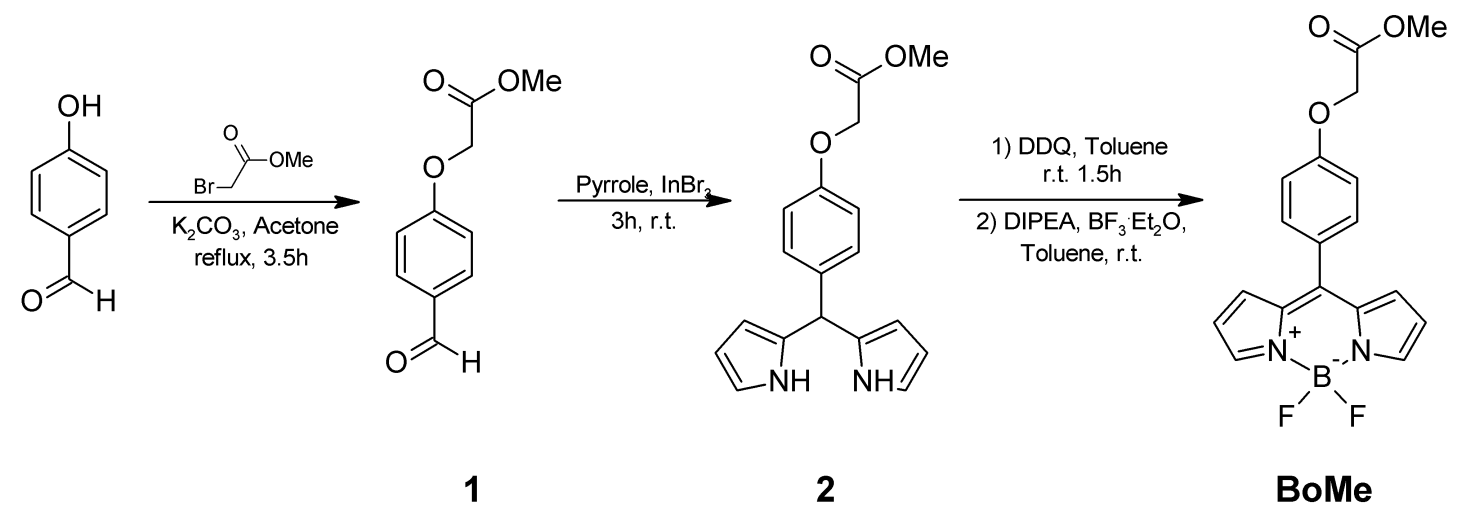

Scheme 1. Synthetic procedure to prepare BoMe

Steady-state optical properties - The steady-state optical features of BoMe were analyzed by steady state absorption and fluorescence in a group of solvents with different polarity and viscosity characteristics (Table 1). In all media, two main absorption bands were observable in the 300-530 nm range (Fig. 1a). The lowest in energy peaked around $500 \mathrm{~nm}$ and was associated with a visible shoulder at $475 \mathrm{~nm}$. This band was assigned to the $S_{01}$ HOMO-LUMO energy transition by comparison with the photophysical data available for a structurally similar Bodipy compound [38]. The sharpness of $\mathrm{S}_{01}$ band $\left(\sim 1000 \mathrm{~cm}^{-1} \mathrm{FWHM}\right)$ seems attributable to the virtually identical geometries of ground and excited states in the Franck-Condon region [38]. We found that the extinction coefficient and wavelength at maximum of $S_{01}$ were slightly affected by the nature of solvent (Table 1). Notably, solvents of higher polarity induced a blue shift in absorption, consistently with the lower electric dipole moment of LUMO as compared to HOMO found in analogs of BoMe [38]. The second, more energetic, band was very broad with maximum around $375 \mathrm{~nm}$ and characterized by about $25 \%$ of the $S_{01}$ intensity. Previous results suggest that this band stems from the overlapping of three distinguishable electronic transitions [38].

As for fluorescence, BoMe showed a single emission in the visible range of the spectrum peaking at about $515 \mathrm{~nm}$ and identifiable with $S_{10}$ transition. The $S_{10}$ band closely mirrors in shape $S_{01}$. This feature and the small Stokes' shift $\left(\sim 580 \mathrm{~cm}^{-1}\right)$ between the two bands are consistent with the rigid and neutral bipyrrin framework that hampers major geometrical relaxations at excited state 12 
associated with emission broadening [39]. In non-viscous solvents the quantum yield of BoMe was found to be rather low (Table 1). This feature has to be attributed to the rotation of the 5-phenyl ring at the excited state. Indeed, previous studies [38] on the BoMe analog lacking the $p$-carboxyester group showed that at the excited state $S_{1}$ the phenyl ring rapidly rotates to reach a conformation coplanar with dipyrrin framework, in order to delocalize the LUMO orbital and to decrease its energy. This conformation corresponds to a maximum in the energy surface of ground state $\mathrm{S}_{0}$, thereby promoting fast and non-radiative $S_{1} \rightarrow S_{0}$ conversion. Yet steric/molecular hindrance hampers the phenyl ring torsion at $S_{1}$, thus modulating the balance between radiative and nonradiative decay. Consistently, increase of the medium viscosity was found to boost the emission of BoMe, as witnessed by the much higher quantum yield detected in viscous Triton-X 100 .

Finally, we should note that the location of $S_{01}$ allows for effective excitation by common laser sources that have emission lines in the $470-496 \mathrm{~nm}$ range. At the same time, $\mathrm{S}_{10}$ parallels the emission of fluorophores widely used in fluorescence imaging (e.g., EGFP). These properties make the excitation and the collection of BoMe emission easy to access for most confocal microscopes.
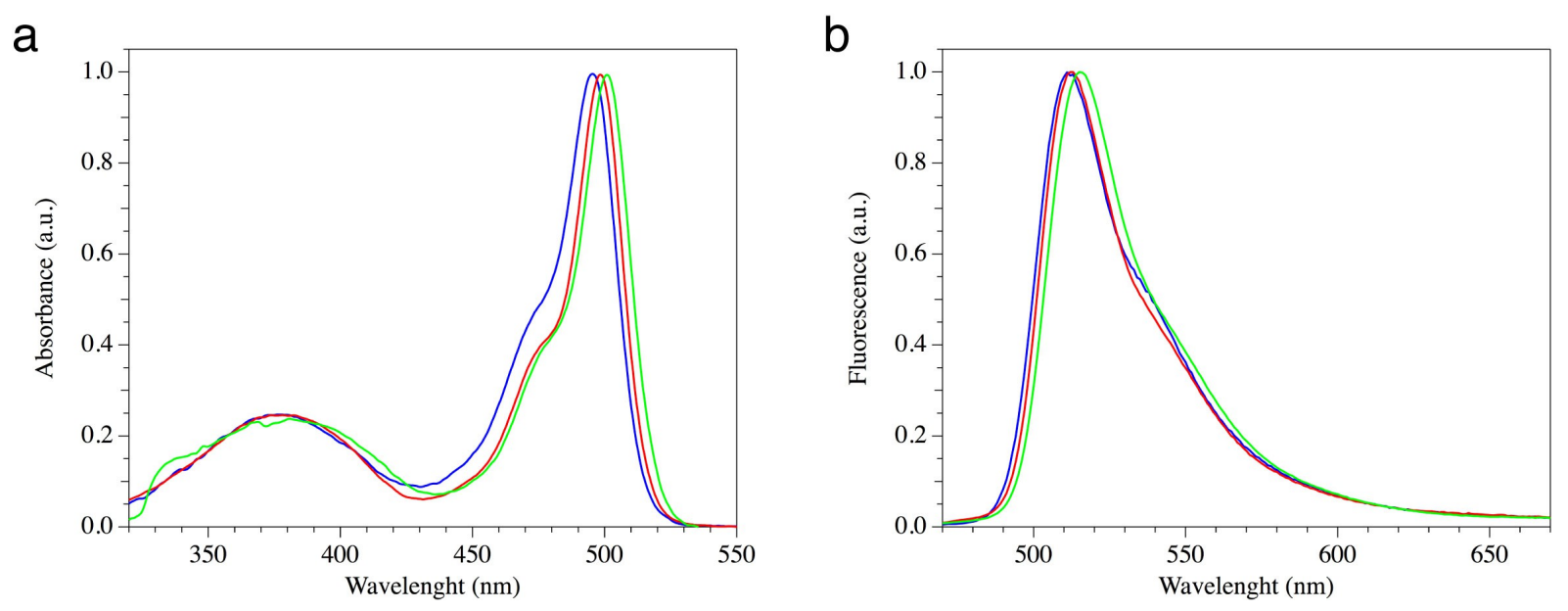

Fig.1. Steady-state optical properties of BoMe. (a) Absorption spectra. (b) Fluorescence emission spectra (excitation: $455 \mathrm{~nm}$ ). Blue line: Cacodylate buffer, $2.5 \mathrm{mM}, \mathrm{pH}=7.0$; red line: isoamyl alcohol; green line: Triton X-100. 
Lifetime dependence on viscosity - Next, we evaluated the viscosity dependence BoMe lifetime emission in two sets of calibration media: medium polarity (MP) mixtures of isoamyl alcohol (IA, $\varepsilon$ $=15.2, \eta=3.7 \mathrm{cP})$ and Triton X-100 (TX, $\varepsilon=5-8, \eta=240 \mathrm{cP})$, and high-polarity (HP) mixtures of methanol (MOH, $\varepsilon=33.6, \eta=0.6 \mathrm{cP})$ and glycerol $(\mathrm{GLY}, \varepsilon=40.1, \eta=945 \mathrm{cP})$. BoMe was excited at $470 \mathrm{~nm}$ by a $40 \mathrm{MHz}$ diode laser in the FLIM setup, and the emission decay collected in the 500$580 \mathrm{~nm}$ range was Fourier-transformed to map into the phasor space. In short, the phasor analysis represents in a polar 2D plot (phasor plot or $A / B$ plot $[40])$ the cosine $\left(g_{i, j}\right)$ and sine $\left(s_{i, j}\right)$ Fourier transforms of the normalized emission decay collected in each pixel $i, j$ of the FLIM image. Beside the components $\left(g_{i, j}, s_{i, j}\right)$, each pixel is characterized by classical frequency-domain lifetime parameters such as phase $\left(\tau_{\mathrm{p}}\right)$ and modulation $\left(\tau_{\mathrm{m}}\right)$ lifetimes. For monoexponential decays, the phasor lies on a semicircle (universal circle) of radius $1 / 2$ and center $(1 / 2,0)$; for multi-exponential decays the phasor lies inside the semicircle. For a phasor lying on the universal circle, $\tau_{\mathrm{p}}$ and $\tau_{\mathrm{m}}$ are the same and identify with the time constant of the associated monoexponential decay.

Inspection of the phasor plot indicated that BoMe is characterized by monoexponential decays regardless of the calibration viscosity, since all phasor clouds fell along the universal circle (Figure 2a) $[18,41]$. The lifetime of BoMe was found to increase as the viscosity was raised, as witnessed by the left-shift of phasor clouds along the universal circle (Figure 2a). This confirmed the rotor behavior of BoMe and its suitability to monitor changes in local viscosity. We plotted the lifetime $v s$. viscosity in a log-log graph to check for linearity (Figure 2b), as predicted by the ForsterHoffmann's equation for a perfect rotor [22]. We found a rather linear correlation between $\log (\tau)$ and $\log (\eta)\left(\right.$ MP: $\chi^{2}=0.891$, HP: $\left.\chi^{2}=0.983\right)$ for both kind of calibration mixtures, different slopes were calculated (MP: 0.29 \pm 0.06 , HP: $0.53 \pm 0.04$ ). This behavior indicates a stronger interaction with HP mixture components that leads to a more significant kinetic restriction of phenyl ring rotation at 
$\mathrm{S}_{1}$ state. Notably, a similar HP slope was reported for a structurally related Bodipy rotor in glycerolbased mixtures [7].

a

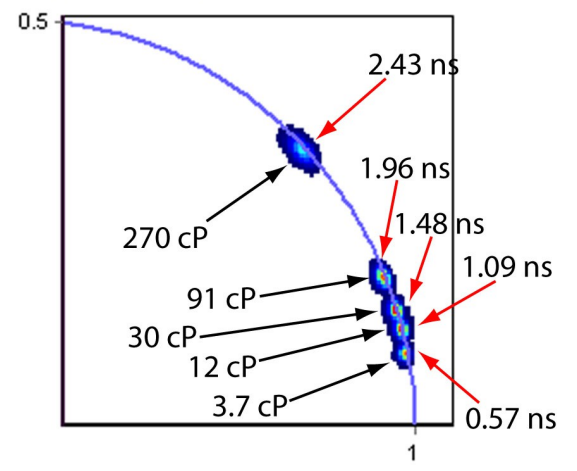

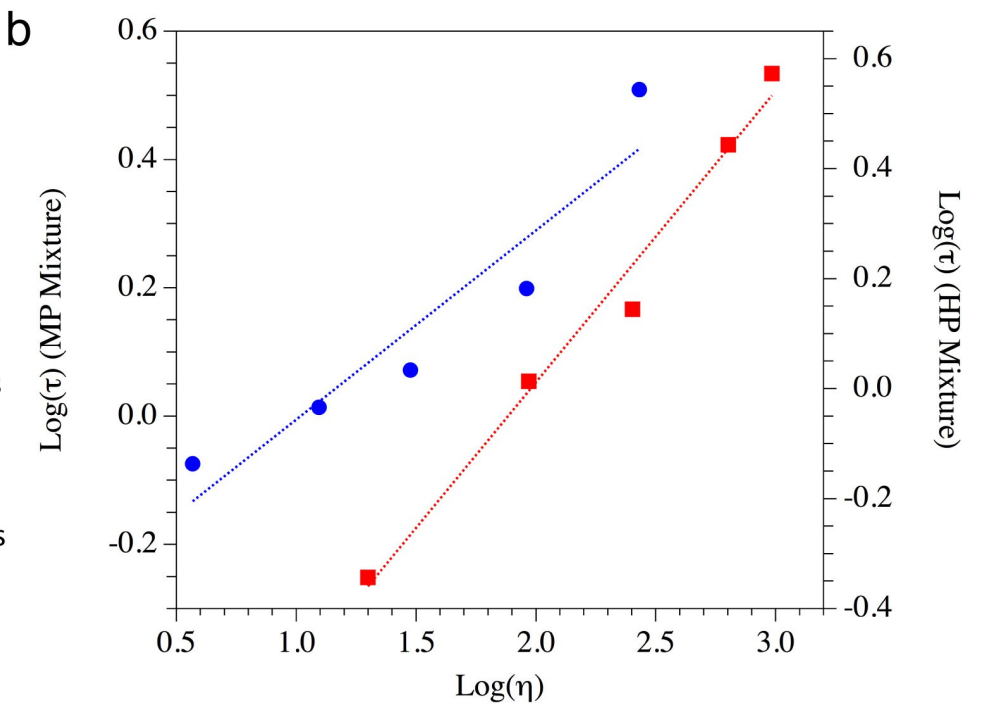

Fig. 2. Dependence of BoMe lifetime on viscosity. (a) Phasor plot displaying the phasor clouds relevant to FLIM of BoMe in MP calibration mixture (see text for details): viscosity and average lifetime values for each phasor cloud are displayed in the panel; (b) Forster-Hoffmann plot reporting $\log (\tau) v s . \log (\eta)$ for BoMe in MP (lifetime on left axis, blue dots) and HP (lifetime on right axis, red dots) mixtures: linear fits (dashed lines) are also included.

Intracellular localization of BoMe - Next, BoMe was added to the external buffer of U2OS cells and its intracellular distribution was evaluated by confocal imaging. Within a few minutes from administration, BoMe was found to internalize effectively inside the cells. The dye mostly distributed in the endoplasmic reticulum, in the nuclear envelope, and in internalization vesicles (Figure 3a,b). This partition into membrane organelles follows the moderate lipophilic nature of BoMe, and it is in agreement with the intracellular distribution of other neutral and lipophilic dyes [4]. Yet, significant fluorescence was detected also in the nucleoplasm (Figure 3a), indicating 
permeation of the dye in this domain and interaction with nuclear components. Minor staining was observed also at plasma membrane level and on filopodia (Figure 3b).
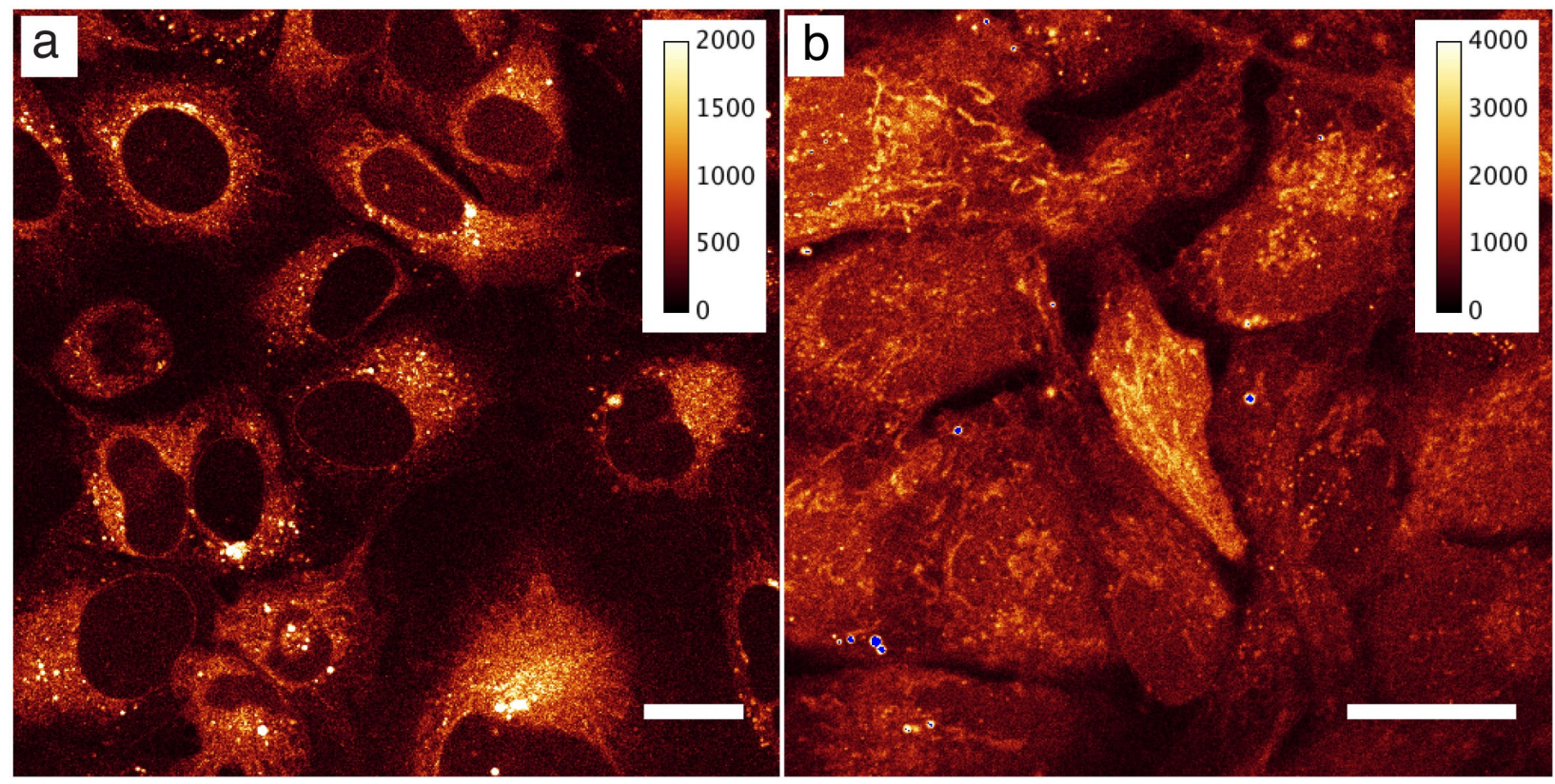

Fig. 3. Intracellular localization of BoMe in U2OS cells as revealed by confocal imaging. (a) Midplane section of cells that shows BoMe partition into the endoplasmic reticulum, vesicles, and nucleoplasm; (b) Basal section of cells that shows partition into endoplasmic reticulum and plasma membrane. Scale bar: $20 \mu \mathrm{m}$.

Interaction of BoMe with DNA - On account of the visible localization of BoMe in the nucleoplasm, we set out to determine whether the dye can bind to double stranded DNA, and the strength of this interaction. For this goal, we carried out fluorescence titrations of BoMe with calf thymus DNA, the latter being a common model for in vivo interaction of the dye with nuclear DNA $[42,43]$. We found out that the fluorescence emission of BoMe increased upon addition of increasing amounts of DNA; the relevant binding isotherm is shown in Fig. $4\left(\Delta \mathrm{F}=\mathrm{F}-\mathrm{F}^{\circ}\right.$ where $\mathrm{F}^{\circ}$ is the fluorescence emission in the absence of DNA). This behavior confirmed the interaction between the dye and DNA. 

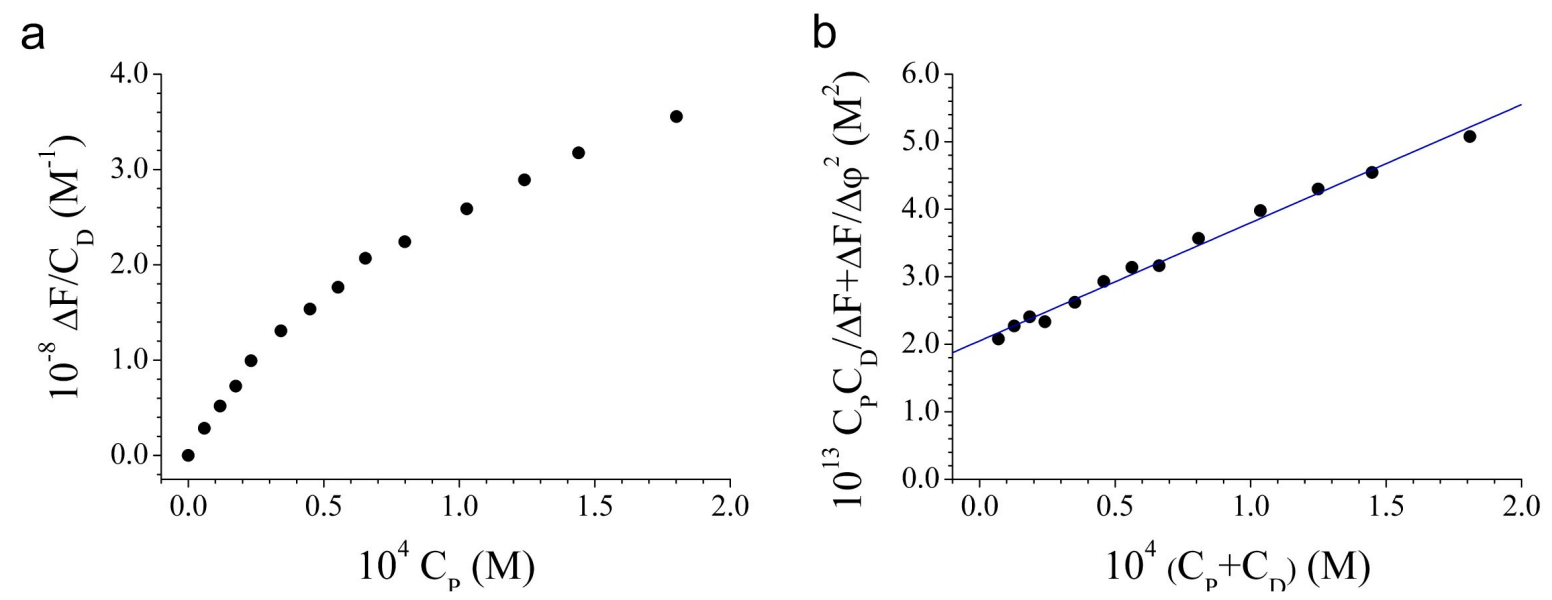

Fig. 4. (a) Binding isotherm from a fluorescence titration of the BoMe/DNA system and (b) relevant data analysis according to equation (1); $\mathrm{C}_{\mathrm{BoMe}}=\mathrm{C}_{\mathrm{D}}=1.0 \mu \mathrm{M}, \lambda_{\mathrm{ex}}=470 \mathrm{~nm}, \lambda_{\mathrm{em}}=512 \mathrm{~nm}$, $\mathrm{pH}=7.0(2.5 \mathrm{mM}$ sodium Cacodylate $), \mathrm{T}=25^{\circ} \mathrm{C}$.

The data were analyzed according to the equation below

where $\Delta \varphi=\varphi_{\mathrm{PD}}-\varphi_{\mathrm{D}}, \varphi_{\mathrm{i}}$ is optical parameter of the $\mathrm{i}$-species and $\mathrm{K}$ is the equilibrium constant for the binding of the DNA polymer (P) to BoMe dye (D) to give the complex (PD) [44]. Equation (1) holds as, under the diluted conditions of experiment, fluorescence emission of the $\mathrm{i}$-th species is proportional to the species concentration: $F_{i}=\varphi_{i} \cdot[i]$. From the analysis we calculated $K=$ $(8.5 \pm 0.4) \cdot 10^{3} \mathrm{M}^{-1}$ in $2.5 \mathrm{mM}$ sodium cacodylate buffer, $\mathrm{pH}=7$. Taking into account that BoMe has an overall neutral charge, the $\mathrm{K}$ value would not significantly depend on the salt content. Thus $\mathrm{K}$ is expected to possess the same value at physiological conditions, i.e. at salt concentrations around $0.1 \mathrm{M}$. The $\mathrm{K}$ value is lower than that shown by classical intercalators as acridine dyes at physiological conditions [45]. On the other hand, this value is higher than what expected for 17 
external binding [ca. $100 \mathrm{M}^{-1}$, [46]]. On the whole, these data suggest that BoMe does interact with DNA according to an intercalation mode where the dye only partially inserts itself between the base pairs.

Effect of HGPS (progeria syndrome) on intracellular viscosity - In cells, type-A lamins (LaAs) are splice variants of the same gene (LMNA). Each LaA undergoes a complex post-translational processing from the precursor molecule prelamin A (pre-LaA) which includes: farnesylation, proteolytic cleavage of the last three amino acids, carboxymethylation, and a second proteolytic removal of the terminal 15 amino acids [31]. In progeria, a specific mutation in LMNA leads to the internal deletion of 50 aminoacids in LaA preventing such post-translational processing. Model cells for progeria can be obtained by transient transfection of mutated LMNA. Following literature, we shall refer to mutated lamin as HGPS [34]. Figure 5 shows the comparison between U2OS cells transiently transfected with wild-type (panel a) and mutated (panel b) LMNA fused to DsRed gene to provide fluorescence staining at NL level. As clearly visible, HGPS accumulates at NL leading to nuclear architectural defects such as blebs, herniations of nuclear envelope (NE), and thickening of NL [31].
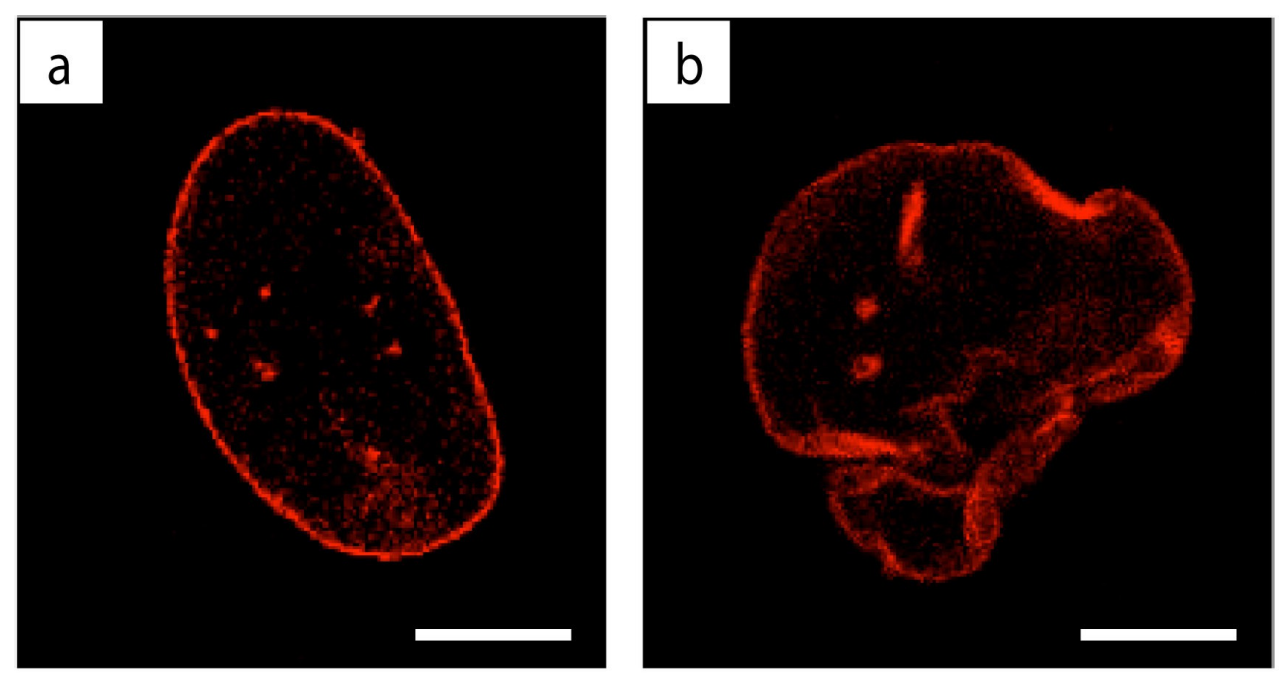

Fig. 5. Confocal images of U2OS transiently expressing (a) DsRed-LaA and (b) DsRed- HGPS. Scale bar: $10 \mu \mathrm{m}$. 
The ability of BoMe to report on local viscosity in the biological context was put to the test in normal or defective U2OS cells as for the transient expression of LaA (normal cells) or HGPS (HGPS cells), respectively. Lifetime images of both normal and HGPS cells were obtained by our confocal FLIM setup and analyzed according to the phasor approach (Fig. 5). Concomitantly, DsRed emission was collected to identify properly the NL and the nuclear domain.

Very remarkably, BoMe showed phasor clouds falling within the universal circle both in normal and HGPS cells (Fig. 6d,j). This indicates that BoMe emission is no more monoexponential, at odds with the decays collected in vitro (Fig. 3). Biexponential decays were indeed reported for a structurally-similar Bodipy rotor when embedded in cellular domains such as membranes [47]. Yet multiexponential decays might be due to aggregation of the dye. To rule out this hypothesis, we measured the emission spectrum of intracellular BoMe in vesicles, where it concentrates strongly, and in cytoplasmic organelles (Fig. 7a,b). These spectra were compared with the emission spectrum collected in TX at $1 \mu \mathrm{M}$ (Fig. 7b). The similarity of shape between the spectra in vitro and in vivo and the absence of significant long-wavelength shoulders [47] are poorly consistent with the presence of any BoMe aggregate in cell.

In both cell types, the phasor clouds of BoMe could be divided into three sub-regions, which are enclosed in squares of different colors in Fig. 6d,j to highlight the corresponding pixels in Fig. 6c,i. The phasors falling into the leftmost square (red, longer lifetimes) belonged to pixels in plasma membranes of the cells (Fig. 6c,d). The other two groups of phasors differ considerably between normal and HGPS cells. In normal cells, the phasors enclosed into the rightmost square (green, shorter lifetimes) reflected pixels relevant to endoplasmic reticulum and nuclear envelope, and the phasors in the central rectangle (blue, intermediate lifetimes) mapped pixels in the nucleus and part 
of the cytoplasm (Fig. 6c,d). This phasor pattern was partially reversed in HGPS cells (Fig. 6i,j), indicating that the altered assembly of lamin A plays a role in the viscosity of cellular domains.
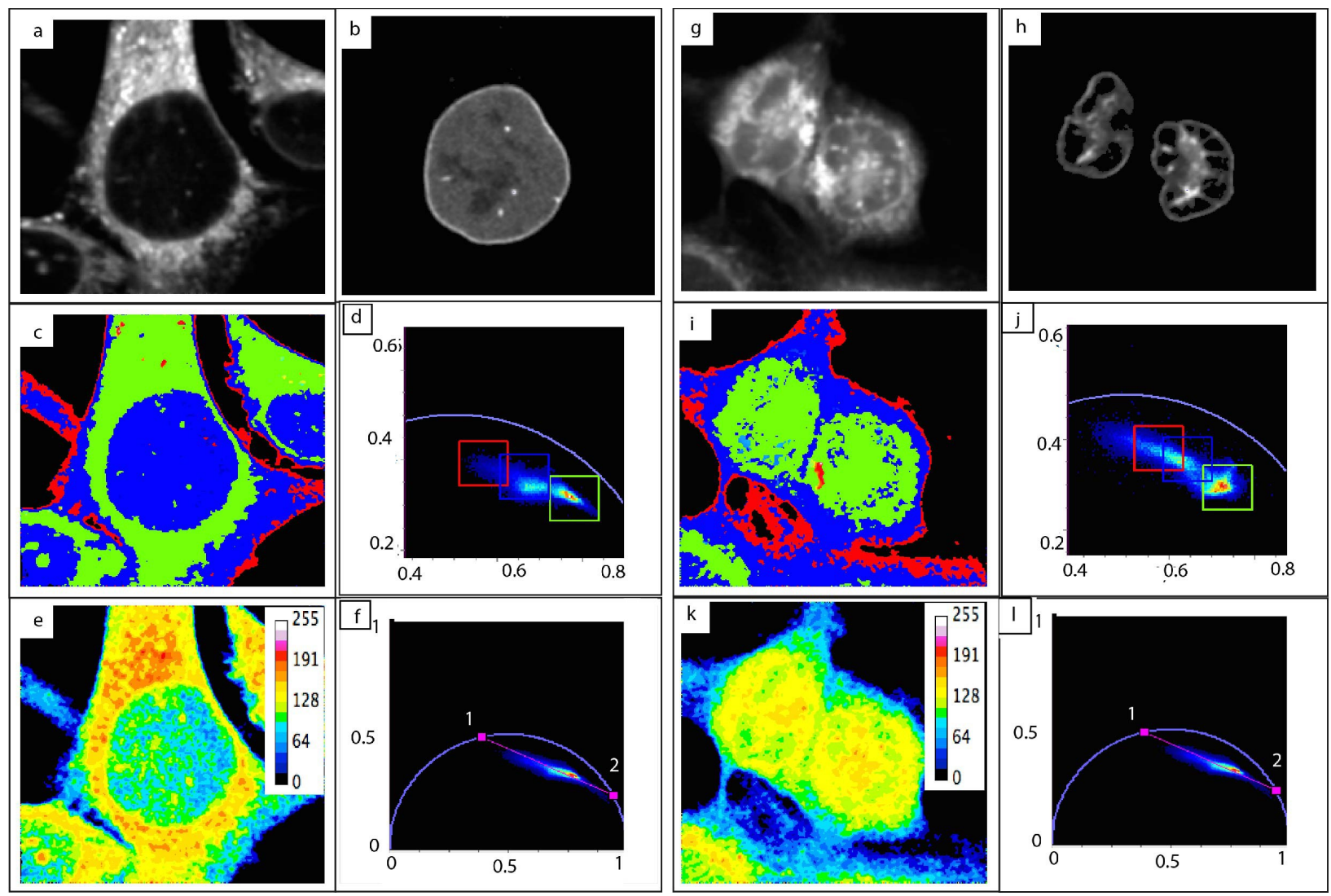

Fig. 6. Phasor analysis of confocal FLIM applied to normal (a-f) and HGPS (g-l) U2OS cells. (a,g) Fluorescence intensity images of BoMe. $(\mathrm{b}, \mathrm{h})$ Fluorescence intensity images of DsRed-LaA. (c,i) Qualitative phasor analysis: pixels corresponding to three phasor regions enclosed by colored squares in phasor plots $(\mathrm{d}, \mathrm{j})$ are highlighted by using the same color. (e,k) Quantitative phasor analysis: pixels were colored according to a scale expressing the fraction of phasor component 2 as calculated from calibrated phasor plots (f,l). For further details see main text. 

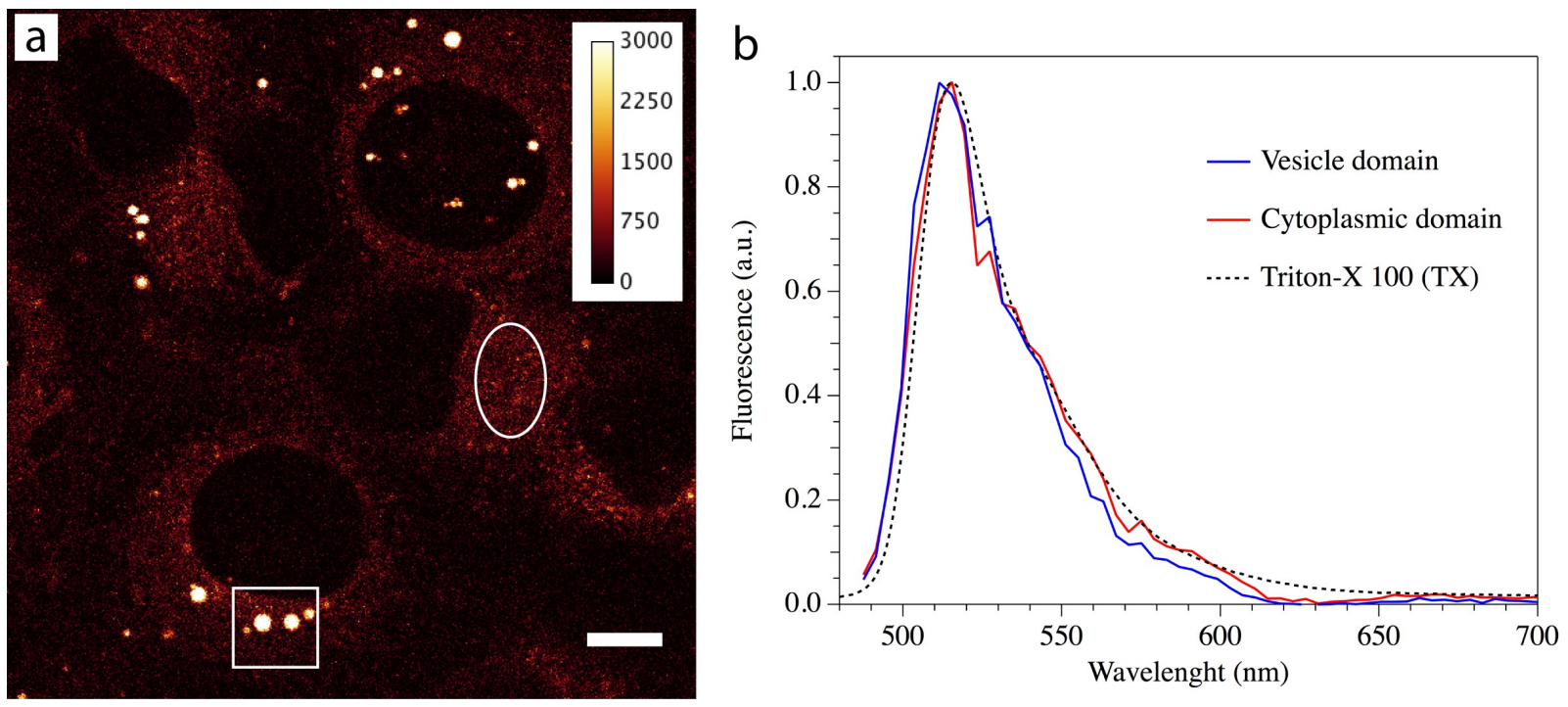

Fig. 7. Spectral analysis of BoMe in vivo and in vitro. (a) Confocal image of U2OS cells stained with BoMe; the emission spectra were measured on highly-emissive vesicles and low-emissive cytoplasm enclosed by a white square and oval, respectively; scale bar: $10 \mu \mathrm{m}$. (b) Normalized emission spectra of vesicle (blue line) and cytoplasmic (red line) domains; the emission spectrum in Triton-X 100 is reported as black dashed line for reference.

A second striking feature of the phasor clouds of both cell types was their almost linear distribution (Fig. 6f,1). This arrangement prompted us to consider each BoMe phasor as an intensity-weighted sum of two reference phasors lying on the universal circle, on account of the vector additivity rule of phasors [14]. The reference phasors $\mathbf{1}$ and $\mathbf{2}$ were identified by the intersections between the universal circle and the linear fit of the global phasor cloud associated with all normal cells. We found that $\mathbf{1}$ and $\mathbf{2}$ correspond to lifetime values $\tau=5.28 \mathrm{~ns}$ and $\tau=1.05$ ns, respectively. The map of intensity fractions relevant to $\mathbf{1}$ and $\mathbf{2}\left(\mathrm{F}_{1}\right.$ and $\left.\mathrm{F}_{2}\right)$ was calculated for each image by simple algebra [48]. As a matter of fact, this approach correspond to a graphical deconvolution of the lifetime decay into two monoexponential components for each pixel of any image [13]. Inspection of the $F_{1}$ or $F_{2}$ maps provided a simple and straightforward way to evaluate 
changes in emission dynamics of BoMe in different intracellular domains. Note that maps of $F_{1}$ and $\mathrm{F}_{2}$ bear the same information, since $\mathrm{F}_{1}=1-\mathrm{F}_{2}$. Comparison of panels e and $\mathrm{k}$ in Fig. 6 shows vividly that HPGS cells are characterized by larger $F_{2}$ in the nucleoplasm $\left(\left\langle F_{2}\right\rangle=0.646, n=16\right)$ as compared with normal cells $\left(\left\langle\mathrm{F}_{2}\right\rangle=0.593, \mathrm{n}=13\right.$ cells $)$. This difference is statistically significant ( $p<0.01$, Fig. 8). Normal and HGPS cells were characterized also by dissimilar $\mathrm{F}_{2}$ in the cytoplasmic domains such as the endoplasmic reticulum and vesicles (Fig. 8).

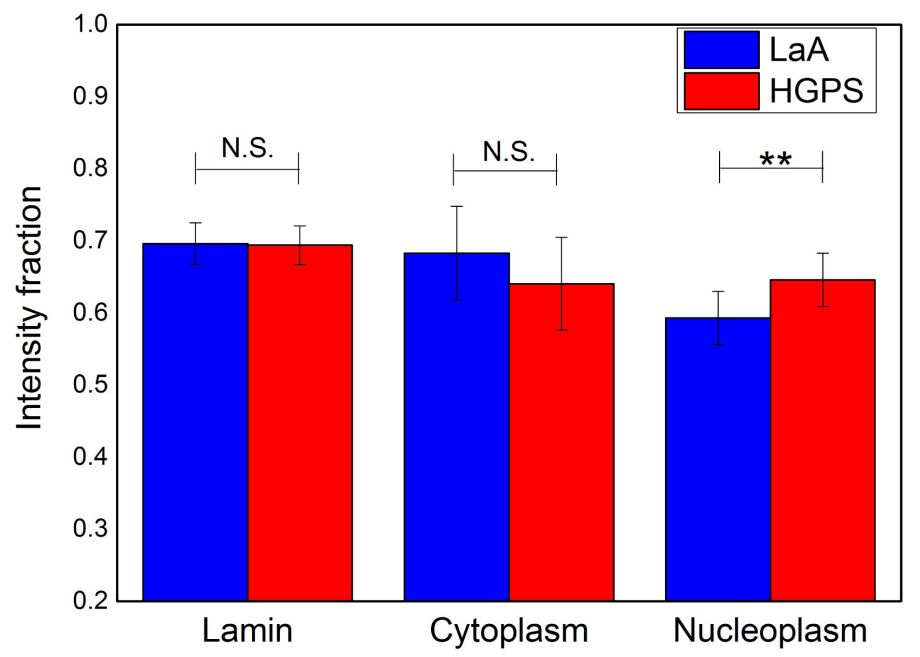

Fig. 8. t-test statistical analysis on $F_{2}$ intensity fractions measured in normal (blue pillars) and HGPS (red pillars) cells. Three different intracellular domains were considered: nuclear lamin, cytoplasm organelles, and nucleoplasm. N.S. $p>0.05, * * p<0.01$.

Yet, this difference is not statistically significant $(p>0.09)$. Impressively, normal and HGPS cells displayed on average the same $F_{2}$ on the nuclear lamina, regardless of the radical difference in morphology of this domain. Taken together, these observations highlight that lamin A misassembly triggers significant variations of local viscosity for nucleoplasmic environments explored by BoMe, which resides presumably along the DNA. This fact suggests a correlation between lamin A misassembly and the chromatin compaction state. Consistently, some authors recently reported that 
HGPS cells are associated with an altered spatial compartmentalization and conformation of chromatin within the nucleus, in some cases losing the classical bipartition into euchromatin and heterochromatin [49]. 


\section{CONCLUSIONS}

In conclusions, we designed a molecular rotor based on Bodipy framework, BoMe, in order to explore viscosity properties at intracellular level. BoMe was synthesized in good yields according to a procedure entailing the condensation between pyrrole moieties and aromatic aldehydes. The steady-state optical characterization demonstrated that fluorescence of BoMe is efficiently excited in the $460-500 \mathrm{~nm}$, and collected in the $500-580 \mathrm{~nm}$ range, thus representing a valuable reporter in typical confocal microscopy conditions. In keeping with the photophysical features of molecular rotors [19], BoMe was associated with a marked increase of its quantum yield and lifetime with environmental viscosity. Remarkably, BoMe lifetime characteristics in vitro and in cellulo were perfectly suited for the phasor approach to lifetime imaging. BoMe rapidly permeated cells and stained cytoplasmic (e.g. endoplasmic reticulum) as well as nuclear domains (e.g. nucleoplasm). Phasor analysis of FLIM applied to cells identified intracellular regions associated with different lifetime, and therefore viscosity, properties. Phasor analysis after calibration highlighted that cells characterized by a genetically-encoded misassembly of lamin A, as observed in Hutchinson-Gilford progeria syndrome (HGPS) [30], were associated with a less viscous nucleoplasm environment as compared with normal cells. On account of the medium-strength interaction of BoMe with DNA here demonstrated in in vitro experiments $\left(\mathrm{K}=8500 \mathrm{M}^{-1}\right)$, we may correlate lamin A misassembly with chromatin compaction. Indeed, HGPS was recently shown to impact on chromatin morphology

and possibly regulation [49]. On overall these results point out the interesting role of BoMe as reporter of intracellular viscosity, particularly at nucleoplasm level. 


\section{AUTHOR INFORMATION}

\section{Corresponding Author}

*Giovanni Signore, ph: +39-050-509699, email: giovanni.signore@ iit.it

*Ranieri Bizzarri, ph: +39-050-509522, email: ranieri.bizzarri@ nano.cnr.it

\section{ACKNOWLEDGMENT}

Dr. Barbara Storti and Dr. Gerardo Abbandonato are gratefully acknowledged for their help in the experimental procedures. This work was supported by the Italian Ministry for University and Research (MiUR) under the framework of the PRIN project 2010BJ23MN_004. 


\section{REFERENCES}

[1] A. Ibraheem, R.E. Campbell, Designs and applications of fluorescent protein-based biosensors, Curr Opin Chem Biol, 14 (2010) 30-36.

[2] D.M. Chudakov, M.V. Matz, S. Lukyanov, K.A. Lukyanov, Fluorescent proteins and their applications in imaging living cells and tissues, Physiol Rev, 90 (2010) 1103-1163.

[3] M.S. Goncalves, Fluorescent labeling of biomolecules with organic probes, Chem Rev, 109 (2009) 190-212.

[4] G. Signore, G. Abbandonato, B. Storti, M. Stockl, V. Subramaniam, R. Bizzarri, Imaging the static dielectric constant in vitro and in living cells by a bioconjugable GFP chromophore analog, Chem. Comm., 49 (2013) 1723-1725.

[5] G. Signore, R. Nifosi, L. Albertazzi, R. Bizzarri, A novel coumarin fluorescent sensor to probe polarity around biomolecules, J. Biomed. Nanotechnol., 5 (2009) 722-729.

[6] G. Signore, R. Nifosi, L. Albertazzi, B. Storti, R. Bizzarri, Polarity-sensitive coumarins tailored to live cell imaging, J Am Chem Soc, 132 (2010) 1276-1288.

[7] M.K. Kuimova, G. Yahioglu, J.A. Levitt, K. Suhling, Molecular rotor measures viscosity of live cells via fluorescence lifetime imaging, J Am Chem Soc, 130 (2008) 6672-6673.

[8] H. Kobayashi, M. Ogawa, R. Alford, P.L. Choyke, Y. Urano, New strategies for fluorescent probe design in medical diagnostic imaging, Chem Rev, 110 (2010) 2620-2640.

[9] A.P. Demchenko, The concept of lambda-ratiometry in fluorescence sensing and imaging, J Fluoresc, 20 (2010) 1099-1128.

[10] M.Y. Berezin, S. Achilefu, Fluorescence lifetime measurements and biological imaging, Chem Rev, 110 (2010) 2641-2684.

[11] K. Suhling, P.M. French, D. Phillips, Time-resolved fluorescence microscopy, Photochem Photobiol Sci, 4 (2005) 13-22.

[12] W. Becker, Fluorescence lifetime imaging - techniques and applications, Journal of microscopy, 247 (2012) 119-136.

[13] M.A. Digman, V.R. Caiolfa, M. Zamai, E. Gratton, The phasor approach to fluorescence lifetime imaging analysis, Biophys. J., 94 (2008) L14-16.

[14] D.M. Jameson, E. Gratton, R.D. Hall, The measurement and analysis of heterogeneous emissions by multifrequency phase and modulation fluorometry, Applied Spectroscopy Reviews, 20 (1984) 55-106.

[15] C. Stringari, A. Cinquin, O. Cinquin, M.A. Digman, P.J. Donovan, E. Gratton, Phasor approach to fluorescence lifetime microscopy distinguishes different metabolic states of germ cells in a live tissue, Proc. Natl. Acad. Sci. U S A, 108 (2011) 13582-13587.

[16] E. Hinde, M.A. Digman, K.M. Hahn, E. Gratton, Millisecond spatiotemporal dynamics of FRET biosensors by the pair correlation function and the phasor approach to FLIM, Proc. Natl. Acad. Sci. U S A, 110 (2013) 135-140.

[17] A. Battisti, M.A. Digman, E. Gratton, B. Storti, F. Beltram, R. Bizzarri, Intracellular pH measurements made simple by fluorescent protein probes and the phasor approach to fluorescence lifetime imaging, Chem. Comm., 48 (2012) 5127-5129.

[18] A. Battisti, S. Panettieri, G. Abbandonato, E. Jacchetti, F. Cardarelli, G. Signore, F. Beltram, R. Bizzarri, Imaging intracellular viscosity by a new molecular rotor suitable for phasor analysis of fluorescence lifetime, Anal. Bioanal. Chem., 405 (2013) 6223-6233.

[19] M.K. Kuimova, Mapping viscosity in cells using molecular rotors, Phys Chem Chem Phys, 14 (2012) 12671-12686.

[20] M.A. Haidekker, E.A. Theodorakis, Molecular rotors--fluorescent biosensors for viscosity and flow, Org Biomol Chem, 5 (2007) 1669-1678.

[21] M.T. Stockl, R. Bizzarri, V. Subramaniam, Studying Membrane Properties Using Fluorescence Lifetime Imaging Microscopy (FLIM), in: Y. Mély, G. Duportail (Eds.) Properties and Functions of 
Biological Membranes Investigated by Fluorescence Methods, Springer, Berlin Heidelberg, 2012, pp. 215-240.

[22] T. Forster, G. Hoffmann, Viscosity Dependence of Fluorescent Quantum Yields of Some Dye Systems, Zeitschrift Fur Physikalische Chemie-Frankfurt, 75 (1971) 63-\&.

[23] F.R. Li, S.I. Yang, Y.Z. Ciringh, J. Seth, C.H. Martin, D.L. Singh, D.H. Kim, R.R. Birge, D.F. Bocian, D. Holten, J.S. Lindsey, Design, synthesis, and photodynamics of light-harvesting arrays comprised of a porphyrin and one, two, or eight boron-dipyrrin accessory pigments, J Am Chem Soc, 120 (1998) 10001-10017.

[24] H. Sunahara, Y. Urano, H. Kojima, T. Nagano, Design and synthesis of a library of BODIPYbased environmental polarity sensors utilizing photoinduced electron-transfer-controlled fluorescence ON/OFF switching, J Am Chem Soc, 129 (2007) 5597-5604.

[25] P. Bianchini, F. Cardarelli, M. Di Luca, A. Diaspro, R. Bizzarri, Nanoscale Protein Diffusion by STED-Based Pair Correlation Analysis, PLoS ONE, 9 (2014).

[26] F. Cardarelli, L. Tosti, M. Serresi, F. Beltram, R. Bizzarri, Fluorescent Recovery after Photobleaching (FRAP) Analysis of Nuclear Export Rates Identifies Intrinsic Features of Nucleocytoplasmic Transport, J. Biol. Chem., 287 (2012) 5554-5561.

[27] R. Bizzarri, F. Cardarelli, M. Serresi, F. Beltram, Fluorescence recovery after photobleaching reveals the biochemistry of nucleocytoplasmic exchange, Anal. Bioanal. Chem., 403 (2012) 23392351.

[28] R.D. Goldman, Y. Gruenbaum, R.D. Moir, D.K. Shumaker, T.P. Spann, Nuclear lamins: building blocks of nuclear architecture, Genes \& Development, 16 (2002) 533-547.

[29] T. Shimi, V. Butin-Israeli, S.A. Adam, R.D. Goldman, Nuclear lamins in cell regulation and disease, Cold Spring Harb Symp Quant Biol, 75 (2010) 525-531.

[30] H.J. Worman, Nuclear lamins and laminopathies, J Pathol, 226 (2012) 316-325.

[31] S. Reddy, L. Comai, Lamin A, farnesylation and aging, Exp Cell Res, 318 (2012) 1-7.

[32] M.A. Haidekker, T.P. Brady, D. Lichlyter, E.A. Theodorakis, Effects of solvent polarity and solvent viscosity on the fluorescent properties of molecular rotors and related probes, Bioorg Chem, 33 (2005) 415-425.

[33] R.A. Velapoldi, H.H. Tonnesen, Corrected emission spectra and quantum yields for a series of fluorescent compounds in the visible spectral region, J Fluoresc, 14 (2004) 465-472.

[34] (!!! INVALID CITATION !!!).

[35] T. Biver, D. Lombardi, F. Secco, M.R. Tine, M. Venturini, A. Bencini, A. Bianchi, B.

Valtancoli, Kinetic and equilibrium studies on the polyazamacrocycle neotetren: metal-complex formation and DNA interaction, Dalton T, (2006) 1524-1533.

[36] G. Felsenfeld, S.Z. Hirschman, A neighbor-interaction analysis of the hypochromism and spectra of DNA, Journal of Molecular Biology, 13 (1965) 407-427.

[37] A. Loudet, K. Burgess, BODIPY dyes and their derivatives: Syntheses and spectroscopic properties, Chem Rev, 107 (2007) 4891-4932.

[38] H.L. Kee, C. Kirmaier, L.H. Yu, P. Thamyongkit, W.J. Youngblood, M.E. Calder, L. Ramos, B.C. Noll, D.F. Bocian, W.R. Scheidt, R.R. Birge, J.S. Lindsey, D. Holten, Structural control of the photodynamics of boron-dipyrrin complexes, J Phys Chem B, 109 (2005) 20433-20443.

[39] Y.H. Chen, J.Z. Zhao, H.M. Guo, L.J. Xie, Geometry Relaxation-Induced Large Stokes Shift in Red-Emitting Borondipyrromethenes (BODIPY) and Applications in Fluorescent Thiol Probes, J. Org. Chem., 77 (2012) 2192-2206.

[40] A.H. Clayton, Q.S. Hanley, P.J. Verveer, Graphical representation and multicomponent analysis of single-frequency fluorescence lifetime imaging microscopy data, Journal of microscopy, 213 (2004) 1-5.

[41] M. Stefl, N.G. James, J.A. Ross, D.M. Jameson, Applications of phasors to in vitro timeresolved fluorescence measurements, Anal Biochem, 410 (2011) 62-69. 
[42] S.S. Mati, S.S. Roy, S. Chall, S. Bhattacharya, S.C. Bhattacharya, Unveiling the Groove Binding Mechanism of a Biocompatible Naphthalimide-Based Organoselenocyanate with Calf Thymus DNA: An "Ex Vivo" Fluorescence Imaging Application Appended by Biophysical Experiments and Molecular Docking Simulations., J Phys Chem B, 117 (2013) 14655-14665. [43] P. Hazarika, J. Deka, S. Bhola, R.K. Bhola, C. Medhi, O.K. Medhi, DNA binding properties and biological studies of cis-dichloro tetrakis(dimethylsulphoxide)ruthenium(II) complex., Int. J. Drug Des. Discovery, 3 (2012) 907-913.

[44] M.R. Beccia, T. Biver, A. Pardini, J. Spinelli, F. Secco, M. Venturini, N.B. Vazquez, M.P.L. Cornejo, V.I.M. Herrera, R.P. Gotor, The Fluorophore 4 ',6-Diamidino-2-phenylindole (DAPI) Induces DNA Folding in Long Double-Stranded DNA, Chem-Asian J, 7 (2012) 1803-1810. [45] T. Biver, F. Secco, M.R. Tine, M. Venturini, Equilibria and kinetics of the intercalation of Ptproflavine and proflavine into calf thymus DNA, Arch Biochem Biophys, 418 (2003) 63-70.

[46] F.J. Meyer-Almes, D. Porschke, Mechanism of Intercalation into the DNA Double Helix by Ethidium, Biochemistry, 32 (1993) 4246-4253.

[47] Y.L. Wu, M. Stefl, A. Olzynska, M. Hof, G. Yahioglu, P. Yip, D.R. Casey, O. Ces, J. Humpolickova, M.K. Kuimova, Molecular rheometry: direct determination of viscosity in L-o and L-d lipid phases via fluorescence lifetime imaging, Phys Chem Chem Phys, 15 (2013) 1498614993.

[48] K.M. Hirshfield, D. Toptygin, B.S. Packard, L. Brand, Dynamic fluorescence measurements of 2-state systems - applications to Calcium-chelating probes, Anal Biochem, 209 (1993) 209-218.

[49] W. Arancio, G. Pizzolanti, S.I. Genovese, M. Pitrone, C. Giordano, Epigenetic Involvement in Hutchinson-Gilford Progeria Syndrome: A Mini-Review, Gerontology, 60 (2014) 197-203. 